\title{
Epidemiological study of power lines and childhood cancer in the UK: further analyses
}

K J Bunch ${ }^{1,2}$, J Swanson ${ }^{3}$, T J Vincent ${ }^{1}$ and M F G Murphy ${ }^{1,4}$

1

Formerly Childhood Cancer Research Group, University of Oxford, New Richards Building, Old Road Campus, Headington, Oxford, OX3 7LG, UK

2

National Perinatal Epidemiology Unit, Nuffield Department of Population Health, University of Oxford, Old Road Campus, Oxford, OX3 7LF, UK

3

National Grid, 1 Strand, London, WC2N 5EH, UK

4

Nuffield Department of Obstetrics\&Gynaecology, University of Oxford, Women's Centre, Level 3, John Radcliffe Hospital, Oxford, OX3 9DU, UK

E-mail: john.swanson@physics.org

\section{Abstract}

We report further analyses from an epidemiological study of childhood cancer and residence at birth near high-voltage power lines in the UK. These results suggest that the elevated risks for childhood leukaemia that we previously found for overhead power lines may be higher for older age at diagnosis and for myeloid rather than lymphoid leukaemia. There are differences across regions of birth but not forming any obvious pattern. Our results suggest the decline in risk we previously reported from the 1960s to the 2000s is linked to calendar year of birth or of cancer occurrence rather than the age of the power lines concerned. Finally, we update our previous analysis of magnetic fields to include later subjects. 


\section{Introduction}

Since 2005, we have published a series of analyses from a programme of epidemiological investigations into childhood cancer and high-voltage power lines in the UK. The first paper [1] reported on incidence of childhood cancer from 1962-1995 with respect to residential distance at birth from 275 and 400kV overhead power lines in England and Wales. A second paper [2] analysed data relating to calculated magnetic fields from these same power lines. More recently, the dataset was extended to include cases registered up to 2008 and also those with addresses in Scotland. Using this enlarged dataset we considered the possibility of effects extending to greater distances from the power lines and included $132 \mathrm{kV}$ lines as well as 275 and $400 \mathrm{kV}$ lines [3]. A further paper considered emissions of corona ions from these power lines [4] and, most recently, we reported analyses of both distance and calculated magnetic fields from high-voltage underground cables [5].

In the present paper, we report various additional analyses not included in previous papers: three sub-analyses that did not fit naturally into any of the previous papers, a new analysis aimed at shedding extra light on our previous findings, and an update to the previous magnetic-field results.

\section{What our previous analyses have shown}

In our 2005 paper[1], we reported an excess of childhood leukaemia (but not of other childhood cancers)in the vicinity of 275 and $400 \mathrm{kV}$ overhead power lines (OHLs), which extended to $600 \mathrm{~m}$ from the lines, farther than could be accounted for by magnetic fields produced by the OHLs. In our 2014 paper[3], we reported that this excess seemed to occur for $132 \mathrm{kV}$ OHLs as well, although to a lesser extent and extending to a lesser distance, and that the increased incidence observed previously [1] had declined over the decades from the 1960s to the present. The excess did not seem to fit the predictions of the corona-ion hypothesis[4]. No similar excess was seen for underground cables (UGCs)[5]though the power of this analysis was limited so conclusions were more tentative.

These results seem to suggest that there is a factor that can, in some circumstances, lead to raised leukaemia rates in the vicinity of OHLs. This effect can be observed to distances of approximately $600 \mathrm{~m}$ for the largest power lines and to a lesser distance for smaller power lines. It has declined progressively from the 1960sand is now not present at all (relative risk(RR) for residential distances $<200 \mathrm{~m}$ compared to $\geq 1000 \mathrm{mfor}$ all power lines combined,1960s: $4.50,2000 \mathrm{~s}: 0.71$ ). This definitely cannot be the effect of magnetic fields alone, and it seems unlikely that magnetic fields are contributing significantly to the excesses at all.

\section{The analyses presented here}

If there is an aetiological effect of magnetic fields, we would expect both OHLs and UGCs to show that. The magnetic-field effects of the two would be cumulative. But, as analysed in [5], the exposed subjects in our UGC magnetic-field analysis are almost entirely different to the exposed subjects in our OHL magnetic-field analyses, and a combined analysis of magnetic field for OHLs and UGCs would not reveal any new information compared to the two separate analyses.

On the other hand, if there is an aetiological effect that is not magnetic fields, but is something else related to proximity, we would probably not expect that to be the same effect for OHLs and UGCs. We regard the proximity analyses for OHL and UGC as self-contained analyses of two 
different things. Therefore we do not attempt any combined analyses for OHLs and UGC and the analyses presented in this paper are for OHLs alone.

First, we present three subgroup analyses that were not included in any of our earlier papers: by age of child at diagnosis, by subtype of leukaemia, and by region of the country.

Second, we investigate whether the observed declining risk over time from 1962 to 2008 is linked more strongly to calendar year(of birth or of cancer diagnosis)or to the age of the relevant power line.

Third, we present updated magnetic-field calculations. Our 2010 analysis of calculated magnetic fields [2]was performed on the subjects of our 2005 paper, that is, cases diagnosed from 1962 to 1995. For distance, in our 2014 analysis[3], we included later cases, registered up to 2008, and we now report the updated calculated-field analysis including these later subjects.

\section{Generic methods}

All the analyses reported here use the same subjects as the 2014 analysis[3], that is, 53,506 cases of childhood cancer whose details were recorded in the National Registry of Childhood Tumours for children born and diagnosed from 1962 to 2008, and control children individually matched for date of birth, sex, and birth registration subdistrict. Grid references of the mothers' address at the birth of the child are derived from Ordnance Survey products CodePoint and AddressPoint. As in our previous analysis, we include all cases where we have an accurate grid reference from AddressPoint; if we have only the less accurate CodePoint grid reference, we assume the distance is $\geq 1000 \mathrm{~m}$ if the CodePoint distance is $>1500 \mathrm{~m}$ and omit the subject otherwise. Locations and other details of power lines were taken from information supplied by National Grid and other electricity companies. Full details of subjects are given in [3] and of methodology in [6].

We calculate odds ratios as an estimate of relative risk. We analyse the risk by distance from the nearest OHL in existence in the year of the case's birth (all 275 and $400 \mathrm{kV}$ lines, and $132 \mathrm{kV}$ lines in areas where we had data on year of construction for $>80 \%$ lines) relative to the reference category of $\geq 1000 \mathrm{~m}$. We have previously reported results sometimes by finer distance categories (0-50, 50100 , then $100 \mathrm{~m}$ bands) and sometimes by coarser categories (0-200-600-1000 m, with 0-200 m corresponding roughly to where our excess risk was largest, 200-600 $\mathrm{m}$ to where it is still present but smaller, and 600-1000 m to where no excess was found); we present risks for the coarser categories here, but the trend analyses uses the midpoint distances of the finer categories. We calculated risks as a matched analysis using conditional logistic regression and adjusting for socioeconomic status using an area-based measure, quintiles of Carstairs Index of the electoral ward taken from the 1991 census, exactly as for our previous analyses. Given that this adjustment makes little difference in our results, any errors introduced by using this single measure of socioeconomic status, from the middle of the period of our study, are likely to be small.

When we make comparisons to other published results on magnetic fields, we limit ourselves to studies that were included in either the Ahlbom et al [7]or the Kheifets et al [8]pooled analyses of magnetic fields, as this selects those studies that meet specified quality criteria. We also reference recently published French and Danish studies of direct relevance to our results $[9,11,13]$.

\section{Analysis of age at diagnosis}




\subsection{Method}

We analysed risks for distance in subgroups of the case's age at diagnosis: 0, 1-4, 5-9, and 10-14 years.

Because the risk for all ages combined declines over time, there would be little point in reporting a single analysis for the whole time period. We are already dividing the subjects into four subgroups (by age), so further division into decades, as in our previous analysis, would inevitably result in very small numbers. We compromise by analysing in two periods: 1962-1989, roughly the period of birth and diagnosis in which an excess risk was observed, and 1990-2008, roughly the period in which no excess risk was observed.

Our analysis is always in terms of the child's domicile at birth, but we here analyse risk at the age at which the cancer subsequently developed, without knowing whether the child was still resident at the same address.

\subsection{Results and discussion}

The results are shown in table 1 and, for leukaemia only, illustrated in figure 1.This and subsequent figures illustrate the risk using the RR for the closest distance category with the farthest taken as reference group; the alternative of using the RR for trend would be equally valid.

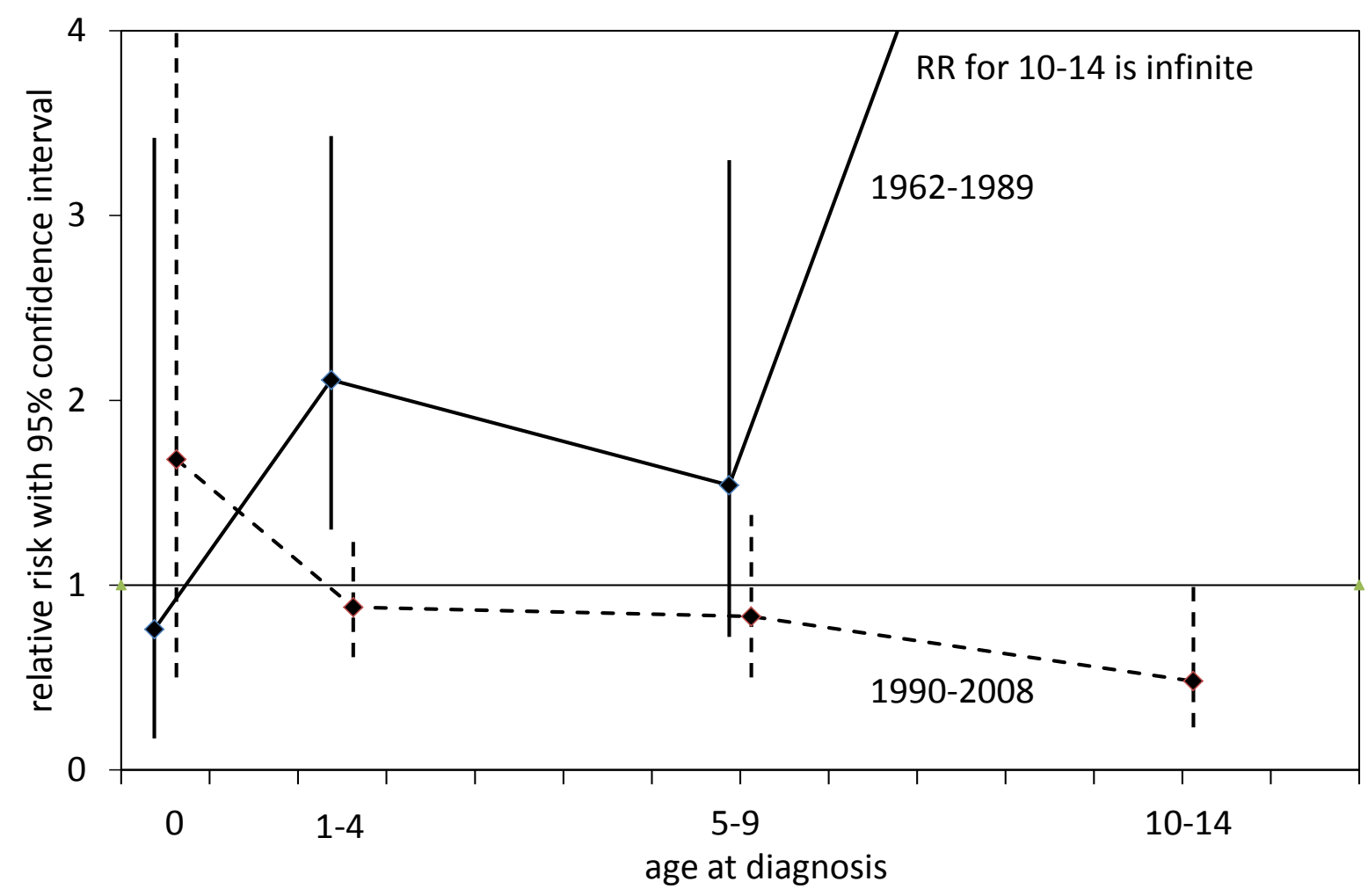

Figure 1

Relative risk for leukaemia for residential address at birth 0-199 $\mathrm{m}$ from power line compared to $\geq 1000 \mathrm{~m}$, by age of case diagnosis, for the two periods of diagnosis. 
For the later period, 1990-2008, no excess risks are evident in any age category, as expected, given that there was no excess risk for all ages combined in this period. For the earlier period, 1962-1989, there are suggestions that there is no excess risk in the age category 0 , with excess risk then increasing with age of case to a maximum in the age category 10-14. Adjustment for socioeconomic status made little difference (unadjusted results not shown).

The statistical power after splitting into multiple subcategories is too low to be at all confident in drawing conclusions. However, taken at face value, this analysis could suggest that any effect of proximity to OHLs operates on the child after their birth, rather than in utero, and therefore is more effective the longer the child is exposed.

A recent French study [9]found elevated risks within $50 \mathrm{~m}$ of powerlines, confined to younger children (RR(95\% Cl), 0-49 m compared to $>600 \mathrm{~m}, 0-4$ years: 2.6 (1.0-6.9), 5-14 years: 1.0 (0.3-3.3), the opposite trend with age to ours. For magnetic fields rather than distance, the Kheifets pooled analysis [8]also weakly suggests the opposite trend to ours: "Risks were a little higher for ... a younger age group" (e.g. RR $(95 \% \mathrm{Cl})$ for $\geq 0.3 \mu \mathrm{T}$ compared to $<0.1 \mu \mathrm{T}$, age at diagnosis $\leq 8: 1.63$ (0.75-3.54), >8: $1.30(0.30-5.63))$. The Ahlbom pooled analysis [7]did not include this analysis and only one component study[10] reported it separately, with no clear pattern.

\section{Analysis by subtype of leukaemia}

\subsection{Method}

For leukaemia, we analysed risks separately for lymphoid leukaemia and for acute myeloid leukaemia (ICCC-3 diagnostic groups la and Ib respectively). Diagnoses are coded according to ICD-O3 and classified by the International Classification of Childhood Cancer, Third Edition (ICCC-3) [11]. Because there are fewer subcategories, we retain the analysis by separate decades, but otherwise, all analytical choices are the same as for the analysis by age.

\subsection{Results and discussion}

The results are shown in table 2 and illustrated in figure 2 . 


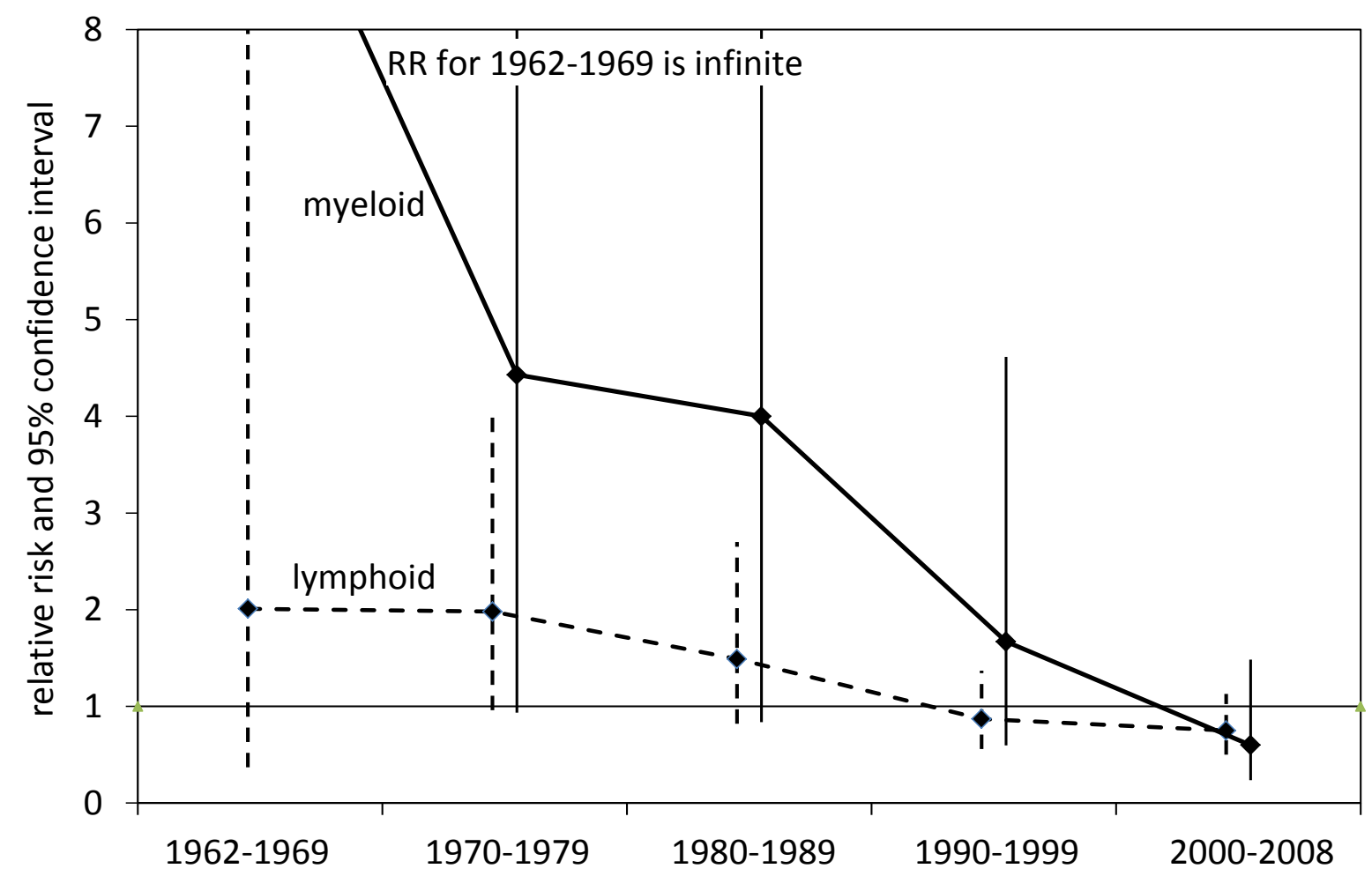

Figure 2

Relative risks for subtype of leukaemia, residential address at birth 0-199 $\mathrm{m}$ from power line compared to $\geq 1000 \mathrm{~m}$, by calendar period of diagnosis.

Lymphoid leukaemia comprises $74 \%$ of our leukaemia cases. There is a clear suggestion that the excess risks observed in the earlier decades are greater for acute myeloid leukaemia than for lymphoid leukaemia, but because the myeloid category is small (reflected by the width of the confidence intervals) this observation must be treated with caution.

Because lymphoid leukaemia is more commonly diagnosed at younger ages, and myeloid at older ages, the previous and the present subgroup analyses, for age of case at diagnosis and for leukaemia subtype, are not fully independent.

In previous studies of magnetic fields, risks were similar for acute lymphocytic leukaemia (ALL) compared to total leukaemia, e.g. Ahlbom RR $(95 \% \mathrm{Cl})>0.4 \mu \mathrm{T}$ compared to $<0.1 \mu \mathrm{T}$, ALL: 2.08 (1.303.33), total leukaemia: 2.00 (1.27-3.13); Kheifets, $>0.3 \mu \mathrm{T}$ compared to <0.1 $\mu \mathrm{T}$, ALL: 1.56 (0.93-2.60), total leukaemia: $1.46(0.80-2.68)$.

None of these analyses are robust enough to draw firm conclusions, but the various results for age and type of leukaemia could suggest that we are observing an effect that operates on different leukaemias or through different mechanisms compared to the elevated risks closer to line observed by others. 
If the effect operates to different extents on different leukaemia subtypes, changes in the proportions of different subtypes over time (either because of actual changes in the rates or because of changing diagnostic practice) would produce a changing overall risk over time. Proportions of different leukaemia subtypes have indeed changed[11]. However, the proportion of myeloid leukaemias, the leukaemia for which our results here suggest the stronger risk, has stayed relatively constant over the period of our study at about 15\%, and the changes in other subtypes (lymphoid increasing from $66 \%$ to around $80 \%$, "other and unspecified" reducing from $18 \%$ to $<5 \%$ ) are not large enough to explain our findings.

\section{Analysis by region of the country}

\subsection{Method}

For leukaemia only, we grouped cases and controls into the ten Office for National Statistics Standard Statistical Regions in which their residential address at birth fell. $3 \%$ of subjects, where the case and control fall in different regions, are dropped from this analysis. Because of multiple categories, we again analysed risks in two time periods, 1962-1989 and 1990-2008.

\subsection{Results and discussion}

The results are shown in table 3 and, for the earlier period where excess risks were observed, illustrated in figure 3 . In the figure, the regions are ordered, post hoc, by the RR.

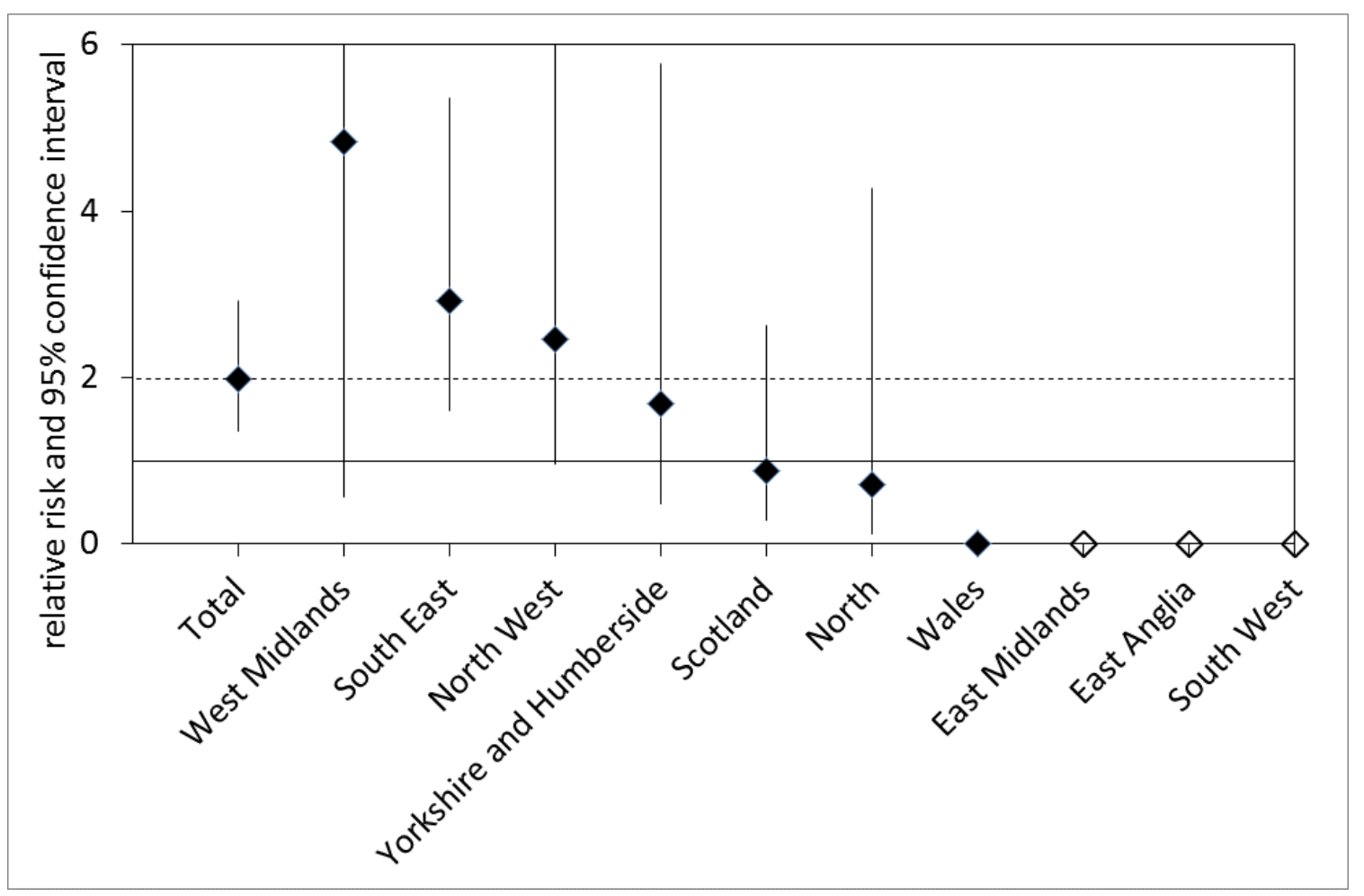

Figure 3

Relative risks for leukaemia, 1962-1989, residential address at birth 0-199 m from power line compared to $\geq 1000 \mathrm{~m}$, total and by Standard Region, ordered by RR. The RR for Wales is zero; for 
the last three regions, there were zero cases, making the RR indeterminate. Dotted line shows the RR for all regions combined.

Risks are higher in some regions than in others, but none differ significantly from the total risk. However, our multivariate analysis of unmatched data reported in section 8 below indicates that the regional effect is heterogeneous. There is no clear pattern to the trend across regions, but perhaps a weak indication that risks may be higher in more urbanised regions. We draw no conclusions from this analysis, but if, in future, a putative risk factor emerged that was linked to geography - perhaps through urbanisation - these results suggest that it could be interesting to test that risk factor with our data.

\section{Investigation of calendar year of birth or diagnosis versus age of line}

Our finding of declining raised risks over time could be interpreted in different ways. It could be interpreted as a calendar-year effect: some aetiological factor was present in the 1960s, has declined over time, and is no longer present in the 2000s. However, many of the power lines concerned were built during the 1950s and 1960s, as shown in figure 4, and thus our highest risks were found in the decades when the power lines were newest. So our finding could also be interpreted as a timefrom-construction effect: the construction of a power line produces a transient effect in its vicinity that lasts a decade or so, producing the declining risk over time we previously discovered.

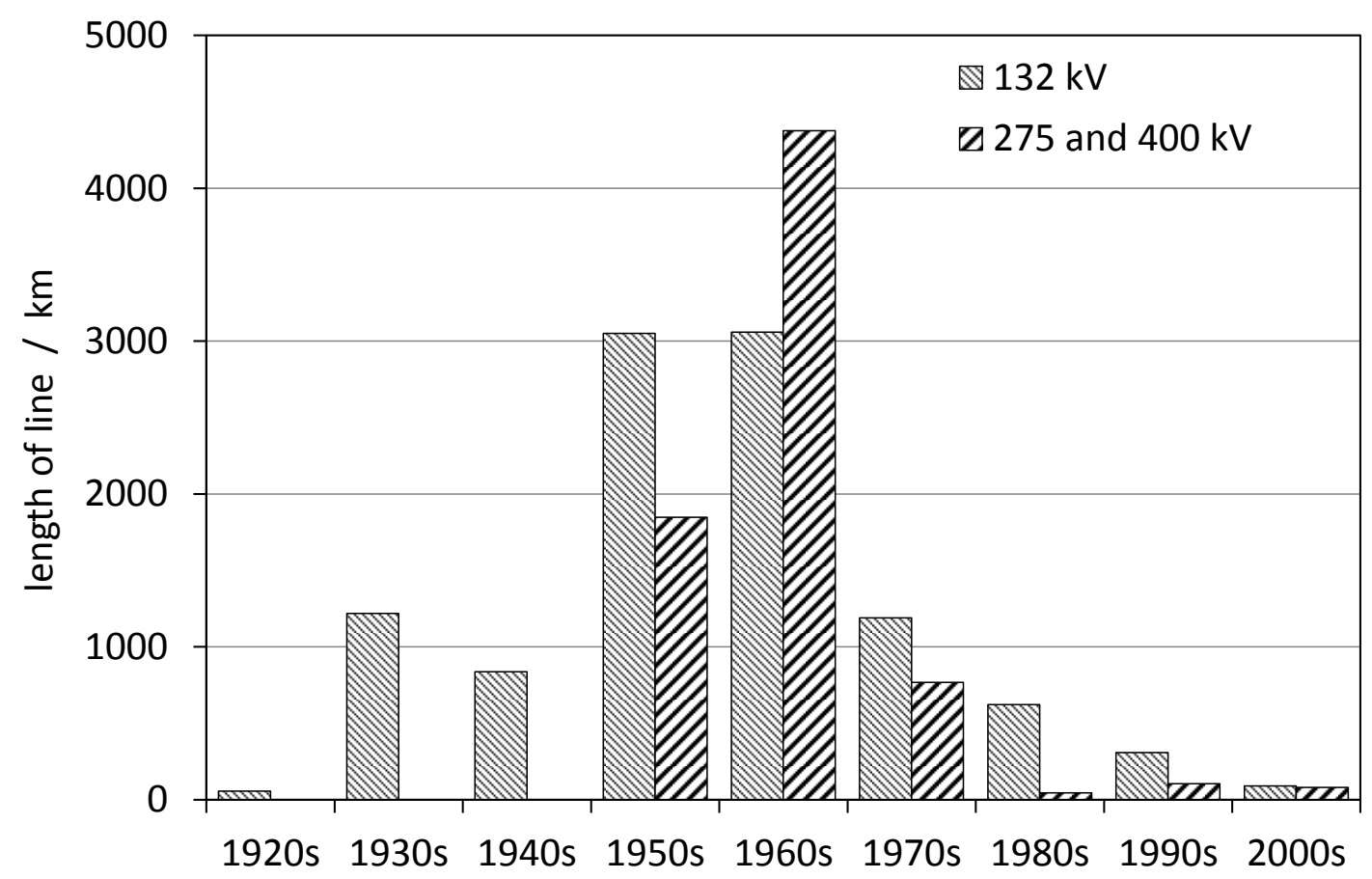

Figure 4

Lengths of power line constructed in each decade (based on all lines with known construction dates; not all of these were used in our analyses). 
These different interpretations would have rather different public-health implications. If the effect is linked to calendar year, either of birth or of cancer occurrence, then it is now no longer present, and any new power lines constructed today would not be expected to produce this effect. If, however, it is a transient effect linked to the construction of a power line, any new power lines constructed today could still be expected to produce this effect. The two variables - calendar year of birth or occurrence, and age of power line - are highly correlated for every type of tumour (Spearman's rank correlation coefficient 0.70 for leukaemia, 0.69 for CNS and 0.69 for "other"), so distinguishing the two alternative effects conclusively is difficult, but we attempted to do so given the public-health importance of the difference.

Our identification of these two alternative interpretations is primarily driven by our data rather than by any mechanistic hypothesis, but declining risks after an initial increase following the introduction of a new facility into an area is characteristic of the Kinlen's population-mixing hypothesis [12]-[14], and an extension of that hypothesis could be one candidate explanation for our data.

\subsection{Method}

Our controls were individually matched to the cases on a number of factors, and all our results to date have been drawn from matched analyses. However, one of the matching factors was date of birth, one of the two variables we now seek to disentangle, making it necessary to perform unmatched analyses. Age of power line will also, in many instances, be different for a case and its matched control(s), making stratification by age of line within a matched analysis impossible. A necessary preliminary was therefore to see if unmatched analyses of our data produced similar results to the previous matched analyses. Table 4 confirms that they do (compare columns $A$ and $B$ ), albeit, in general, with slightly smaller risks, therefore indicating that we are justified in proceeding with unmatched analyses.

We then performed two parallel analyses, one stratified by calendar year of diagnosis and the other by age of power line in the birth year of the case or control. The objective was to make the two analyses as similar as possible, so that any differences between them are attributable solely to the stratification variable. We had stratified calendar year of diagnosis by decades, so we also stratified age of line in ten-year groups since construction. The subjects in the calendar-year analysis are restricted to those subjects that had a known line age (columns $C$ in table 4 ) so that the same subjects appear in both analyses.

In our matched analyses, the matching variable was year of birth. However, when we stratified by decade in our 2014 paper [3], we stratified by decade of diagnosis. In the present analysis, we compare stratification by decade of birth and of diagnosis (table 4 columns $C$ and D). Results are similar, as expected given the generally young age of leukaemia occurrence, with the only suggestion of a difference being in the 1960s, the decade when numbers were smallest. For consistency with our earlier work [3], we retain decade of diagnosis, rather than of birth, as the primary variable that we investigate in the present analysis.

\subsection{Results and discussion}


The results, for leukaemia only, are shown in table 4 (compare columns $\mathrm{C}$ and $\mathrm{E}$ ) and illustrated in figure 5 .

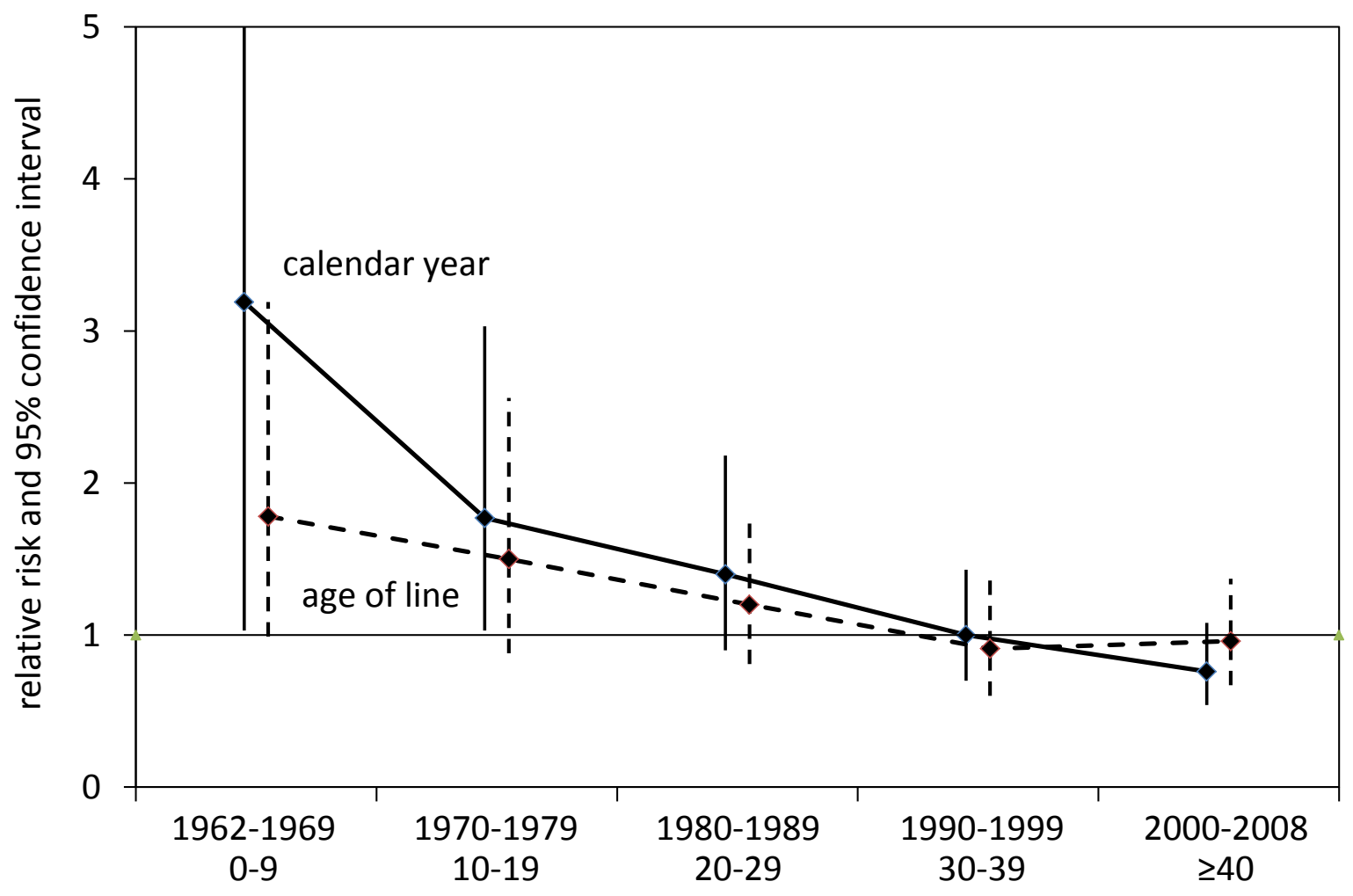

Figure 5

Relative risks for leukaemia, residential address at birth 0-199 $\mathrm{m}$ from power line compared to $\geq 1000 \mathrm{~m}$, stratification by calendar year of diagnosis and age of line compared.

The relative risks give a slight suggestion that calendar year produces more extreme risks than age of line.

However, we also performed a multivariate analysis, using a model with separate variables for decade of calendar year of diagnosis, decade of age of line, and inverse distance from OHL (and also sex, standard region, and SES as measured by quintiles of Carstairs index). The results are shown in table 5. As for the preceding unmatched analysis, we also performed this multivariate analysis for year of birth as well as year of diagnosis, and again, the conclusions are similar for the two variables; results for year of birth not shown. It can be seen that, with both variables fitted simultaneously, calendar year of diagnosis $(P=0.000)$ fits the data much better than age of line $(P=0.923)$. As further confirmation, adding calendar year of diagnosis to a model including age of line significantly improves the fit; the reverse, adding age of line to calendar year of diagnosis, does not significantly improve the fit.

We therefore conclude that it seems more likely that our risks are explained by a factor present in the 1960s and declining thereafter, rather than by a factor present when a new line is constructed and declining thereafter. We therefore also conclude, with similar cautiousness, that we would not 
expect any new power line constructed today to produce equivalent risks. However, with the two variables so highly correlated and producing similar risks when analysed separately, this analysis cannot be definitive.

\section{Analysis of magnetic fields}

We extend our previous analysis of calculated magnetic fields [2], using almost identical methods, to include our later subjects. Exactly as with the previous analysis, this analysis is for 400 and $275 \mathrm{kV}$ lines in England and Wales only. The results are shown in table 6.

Our earlier analysis showed a RR of 2.00 for field strengths of $\geq 0.4 \mu \mathrm{T}$ compared to $<0.1 \mu \mathrm{T}$ albeit with a very wide confidence interval (0.18-22.04). With the addition of the later subjects, the point estimate of the effect of higher field strength is reversed although the reduction in risk is not significant (RR 0.50 (0.15-1.62)), echoing our finding of reduced risk for distance in the later period. However, in our study, as in many others, the numbers of subjects at these elevated fields is too small to be able to draw any reliable conclusions regarding magnetic fields from this or other studies in isolation. The value of this part of our analysis is that the data we have derived on magnetic fields will be available to any future pooled analysis, just as our previous data were included in Kheifets et al[8].

\section{Overall conclusions}

As this is the final paper we plan from this study, we draw some overall conclusions.

We have found some elevated risks for childhood leukaemia associated with OHLs. Considering cancers other than leukaemia, for brain tumours, we have found suggestions of reduced risks for OHLs[1] and elevated risks for UGCs [5], but neither form any persuasive or consistent pattern and we consider that our findings are probably specific to leukaemia. Similar methodology to ours, when applied to adult cancers, also failed to find risks for leukaemia, brain/central nervous system cancers, female breast cancer, or malignant melanoma [15].

The elevated risk that we have found extends to $600 \mathrm{~m}$ from the higher-voltage OHLs and a smaller distance for lower-voltage OHLs, too great a distance to be explicable by magnetic fields. Further, although not robust, we did not find an equivalent risk for UGCs, likewise tending to argue against a magnetic-field effect.

The risk elevation reduced over time from the 1960s to the 2000s (to the extent that it was not present at all in the 2000s, indeed, it would be possible to argue it had turned into a slight reduction by that decade). The new results in this paper suggest that this reduction may be linked to calendar year of birth or cancer diagnosis rather than to the age of the lines.

Our finding could be a chance effect. However, when we first found our effect, we had looked only at 400 and $275 \mathrm{kV}$ lines. When we subsequently looked at the next lower voltage of line, $132 \mathrm{kV}$, we found the same effect, diminishing over time in the same way, but smaller in size and limited to a smaller distance, exactly the behaviour that would be predicted of any effect linked to the voltage or size of the power line. In our minds, this argues quite strongly against chance being the explanation. 
Our finding could, in principle, be caused by a bias in our control selection. Our controls have been selected at different times, for different studies, using different physical techniques, but always from the same source (birth registers) and following the same precise, systematic, seemingly entirely objective, rules. We are unable to conceive of any artefact that could deliver the required bias, including the decline over time, but we acknowledge the possibility. We have no evidence that the geographical matching unit - birth registration subdistrict - has systematically changed over this period, and the large size of these units compared to the distance scale of our results suggests that overmatching could be only a small factor anyway. No subject participation is necessary, so differential participation rates, as found in e.g. studies that require subject agreement to measurements, is not a factor.

We are therefore searching for a causal effect that operates with overhead power lines, but probably not with underground cables. To fit our data, it has to apply to childhood leukaemia but not to other childhood cancers; to extend several hundred metres; to be stronger for higher-voltage power lines; to diminish from the 1960s to the 2000s; and, based on the tentative findings in this paper, possibly to be stronger for myeloid leukaemia than for lymphoid, and stronger for cancers developed at older ages.

Since our first publication, two other studies have looked at the same greater distances that we have examined, which had previously rarely been investigated. A French study [9] found elevated risks for leukaemia but only within $50 \mathrm{~m}$ and not from $50-600 \mathrm{~m}$. The time period covered (2002-2007) was when our risk had disappeared. A Danish study [16] found no significantly increased risks out to 600 $\mathrm{m}$ for $132-400 \mathrm{kV}$ lines, though they reported a non-significant RR of 1.76 for 200-600 m for just 220$400 \mathrm{kV}$ lines which they attributed to chance. That study covered 1968-2006, thus spanning the period during which our risk diminished. They did not present analyses of risks for distance over time, but for calculated magnetic fields [17]for all childhood cancers combined and for leukaemia, they reported reduced risks in a later period, consistent with our findings though based on small numbers. We consider there is insufficient data to tell whether whatever causal effect produces our results is specific to the UK or not. A further replication in California [18] is larger and results are expected in 2016.

We have specifically tested for one candidate causal effect, corona ions[4], and found little support. Numerous other suggestions for direct physical effects have been advanced; none seem very plausible. Building on the Kinlen population-mixing hypothesis, a candidate for an indirect mechanism could be if residential mobility varied with proximity to power lines. Our own investigation [19] of one measure of residential mobility failed to identify any such variation. Nonetheless, these factors are incompletely understood, and our own preferred candidate remains some link between the presence of the power line and socioeconomic or demographic factors in its vicinity.

\section{Acknowledgements}

This study was undertaken as part of a project funded initially by the United Kingdom Department of Health Radiation Protection Research Programme and subsequently by the charity Children with Cancer UK. The Childhood Cancer Research Group (CCRG) also received funding from the Department of Health and the Scottish Ministers. CCRG closed down completely in April 2014.The 
views expressed here are those of the authors and not necessarily those of the Department of Health and the Scottish Ministers. JS is employed by National Grid who provided staff time but no other funding. A written contract exists between CCRG and National Grid specifying that CCRG had complete control over the conduct, interpretation, and publication of this study. This paper has not been approved by anyone in National Grid other than JS in his capacity as author and does not necessarily represent National Grid's views. 


\section{References}

[1] G. Draper, T. Vincent, M. E. Kroll, and J. Swanson, 'Childhood cancer in relation to distance from high voltage power lines in England and Wales: a case-control study', BMJ., vol. 330, no. 7503, p. 1290, Jun. 2005.

[2] M. E. Kroll, J. Swanson, T. J. Vincent, and G. J. Draper, 'Childhood cancer and magnetic fields from high-voltage power lines in England and Wales: a case-control study', Br.J.Cancer, vol. 103, no. 1532-1827 (Electronic), pp. 1122-1127, Sep. 2010.

[3] K. J. Bunch, T. J. Keegan, J. Swanson, T. J. Vincent, and M. F. Murphy, 'Residential distance at birth from overhead high-voltage powerlines: childhood cancer risk in Britain 1962-2008', Br.J.Cancer, vol. 110, no. 1532-1827 (Electronic), pp. 1402-1408, Feb. 2014.

[4] J. Swanson, K. J. Bunch, T. J. Vincent, and M. F. G. Murphy, 'Childhood cancer and exposure to corona ions from power lines: an epidemiological test', J. Radiol. Prot. Off. J. Soc. Radiol. Prot., vol. 34, no. 4, pp. 873-889, Dec. 2014.

[5] K. J. Bunch, J. Swanson, T. J. Vincent, and M. F. G. Murphy, 'Magnetic fields and childhood cancer: an epidemiological investigation of the effects of high-voltage underground cables', J. Radiol. Prot. Off. J. Soc. Radiol. Prot., vol. 35, no. 3, pp. 695-705, Sep. 2015.

[6] J. Swanson, 'Methods used to calculate exposures in two epidemiological studies of power lines in the UK', J.Radiol.Prot., vol. 28, no. 0952-4746 (Print), pp. 45-59, Mar. 2008.

[7] A. Ahlbom, N. Day, M. Feychting, E. Roman, J. Skinner, J. Dockerty, M. S. Linet, M. McBride, J. Michaelis, J. Olsen, T. Tynes, and P. Verkasalo, 'A pooled analysis of magnetic fields and childhood leukaemia', Br. J. Cancer, vol. 83, no. 5, pp. 692-698, 2000.

[8] L. Kheifets, A. Ahlbom, C. M. Crespi, G. Draper, J. Hagihara, R. M. Lowenthal, G. Mezei, S. Oksuzyan, J. Schuz, J. Swanson, A. Tittarelli, M. Vinceti, and F. Wunsch V., 'Pooled analysis of recent studies on magnetic fields and childhood leukaemia', Br.J.Cancer, vol. 103, no. 15321827 (Electronic), pp. 1128-1135, Sep. 2010.

[9] C. Sermage-Faure, C. Demoury, J. Rudant, S. Goujon-Bellec, A. Guyot-Goubin, F. Deschamps, D. Hemon, and J. Clavel, 'Childhood leukaemia close to high-voltage power lines--the Geocap study, 2002-2007', Br. J. Cancer, vol. 108, no. 9, pp. 1899-1906, May 2013.

[10] M. Feychting and A. Ahlbom, 'Magnetic Fields and Cancer in Children Residing Near Swedish High-voltage Power Lines', Am. J. Epidemiol., vol. 138, no. 7, 1993.

[11] C. Stiller, Ed., Childhood Cancer in Britain: Incidence, survival, mortality. Oxford: Oxford University Press, 2007.

[12] L. Kinlen, 'Evidence for an infective cause of childhood leukaemia: Comparison of a Scottish new town with nuclear reprocessing sites in Britain', The Lancet, no. 10 December, 1988.

[13] L. J. Kinlen, 'Epidemiological evidence for an infective basis in childhood leukaemia', Br.J.Cancer, vol. 71, no. 0007-0920 (Print), pp. 1-5, Jan. 1995.

[14] L. J. Kinlen, 'An examination, with a meta-analysis, of studies of childhood leukaemia in relation to population mixing.', Br. J. Cancer, vol. 107, no. 7, pp. 1163-1168, Sep. 2012.

[15] P. Elliott, G. Shaddick, M. Douglass, H. K. de, D. J. Briggs, and M. B. Toledano, 'Adult cancers near high-voltage overhead power lines', Epidemiology, vol. 24, no. 1531-5487 (Electronic), pp. 184-190, Mar. 2013.

[16] C. Pedersen, O. Raaschou-Nielsen, N. H. Rod, P. Frei, A. H. Poulsen, C. Johansen, and J. Schüz, 'Distance from residence to power line and risk of childhood leukemia: a population-based case-control study in Denmark', Cancer Causes Control CCC, vol. 25, no. 2, pp. 171-177, Feb. 2014.

[17] C. Pedersen, C. Johansen, J. Schüz, J. H. Olsen, and O. Raaschou-Nielsen, 'Residential exposure to extremely low-frequency magnetic fields and risk of childhood leukaemia, CNS tumour and lymphoma in Denmark', Br. J. Cancer, vol. 113, no. 9, pp. 1370-1374, Nov. 2015.

[18] L. Kheifets, C. M. Crespi, C. Hooper, S. Oksuzyan, M. Cockburn, T. Ly, and G. Mezei, 'Epidemiologic study of residential proximity to transmission lines and childhood cancer in 
California: description of design, epidemiologic methods and study population', J. Expo. Sci. Environ. Epidemiol., vol. 25, no. 1, pp. 45-52, Jan. 2015.

[19] J. Swanson, 'Residential mobility of populations near UK power lines and implications for childhood leukaemia.', J. Radiol. Prot., vol. 33, no. 3, Sep. 2013. 


\begin{tabular}{|c|c|c|c|c|c|c|c|c|c|c|c|c|c|c|}
\hline \multirow{2}{*}{$\begin{array}{l}\text { Age of } \\
\text { case }\end{array}$} & \multirow{2}{*}{$\begin{array}{l}\text { Year of } \\
\text { diagnosis } \\
\text { of case }\end{array}$} & \multirow{2}{*}{$\begin{array}{l}\text { Distance } \\
\text { to line }(\mathrm{m})\end{array}$} & \multicolumn{4}{|c|}{ Leukaemia } & \multicolumn{4}{|c|}{ CNS/Brain tumours } & \multicolumn{4}{|c|}{ Other diagnoses } \\
\hline & & & Cases & Controls & $\mathrm{RR}$ & $95 \% \mathrm{Cl}$ & Cases & Controls & $\mathrm{RR}$ & $95 \% \mathrm{Cl}$ & Cases & Controls & $\mathrm{RR}$ & $95 \% \mathrm{Cl}$ \\
\hline \multirow[t]{12}{*}{0} & \multirow{6}{*}{$\begin{array}{l}1962- \\
1989\end{array}$} & $0-199$ & 5 & 5 & 0.76 & $0.17-3.42$ & 8 & 6 & 1.00 & $0.29-3.47$ & 14 & 24 & 0.55 & $0.26-1.20$ \\
\hline & & $200-599$ & 30 & 28 & 1.00 & $0.54-1.87$ & 24 & 22 & 1.07 & $0.54-2.12$ & 91 & 87 & 1.08 & $0.76-1.52$ \\
\hline & & $600-999$ & 29 & 45 & 0.65 & $0.39-1.09$ & 17 & 23 & 0.82 & $0.39-1.70$ & 109 & 112 & 0.93 & $0.68-1.27$ \\
\hline & & $\geq 1000$ & 520 & 506 & 1.00 & & 377 & 376 & 1.00 & & 1552 & 1544 & 1.00 & \\
\hline & & total & 584 & 584 & & & 426 & 427 & & & 1766 & 1767 & & \\
\hline & & trend & & & 0.62 & $0.27-1.44$ & & & 1.14 & $0.67-1.94$ & & & 0.83 & $0.59-1.15$ \\
\hline & \multirow{6}{*}{$\begin{array}{l}1990- \\
2008\end{array}$} & $0-199$ & 7 & 11 & 1.68 & $0.50-5.66$ & 3 & 8 & 0.37 & $0.08-1.78$ & 20 & 36 & 0.76 & $0.40-1.44$ \\
\hline & & $200-599$ & 30 & 35 & 1.06 & $0.61-1.84$ & 27 & 41 & 1.08 & $0.60-1.93$ & 107 & 108 & 1.47 & $1.07-2.02$ \\
\hline & & $600-999$ & 44 & 54 & 1.19 & $0.75-1.88$ & 34 & 47 & 0.98 & $0.60-1.58$ & 89 & 169 & 0.78 & $0.58-1.04$ \\
\hline & & $\geq 1000$ & 448 & 670 & 1.00 & & 401 & 582 & 1.00 & & 1325 & 1977 & 1.00 & \\
\hline & & total & 529 & 770 & & & 465 & 678 & & & 1541 & 2290 & & \\
\hline & & trend & & & 1.26 & $0.64-2.47$ & & & 0.89 & $0.51-1.54$ & & & 0.89 & $0.64-1.24$ \\
\hline \multirow[t]{12}{*}{$1-4$} & \multirow{6}{*}{$\begin{array}{l}1962- \\
1989\end{array}$} & $0-199$ & 69 & 31 & 2.11 & $1.30-3.43$ & 22 & 19 & 1.20 & $0.59-2.43$ & 41 & 53 & 0.74 & $0.46-1.17$ \\
\hline & & 200-599 & 189 & 176 & 1.07 & $0.85-1.35$ & 90 & 88 & 1.07 & $0.76-1.51$ & 197 & 203 & 0.97 & $0.77-1.22$ \\
\hline & & 600-999 & 255 & 270 & 0.99 & $0.82-1.21$ & 130 & 121 & 1.07 & $0.80-1.43$ & 238 & 267 & 0.86 & $0.71-1.04$ \\
\hline & & $\geq 1000$ & 3894 & 3934 & 1.00 & & 1731 & 1748 & 1.00 & & 3677 & 3636 & 1.00 & \\
\hline & & total & 4407 & 4411 & & & 1973 & 1976 & & & 4153 & 4159 & & \\
\hline & & trend & & & 1.12 & $0.89-1.40$ & & & 0.91 & $0.67-1.25$ & & & 0.91 & $0.75-1.12$ \\
\hline & \multirow{6}{*}{$\begin{array}{l}1990- \\
2008\end{array}$} & $0-199$ & 57 & 85 & 0.88 & $0.61-1.28$ & 34 & 28 & 1.50 & $0.84-2.67$ & 53 & 65 & 1.18 & $0.76-1.84$ \\
\hline & & 200-599 & 218 & 329 & 0.93 & $0.77-1.14$ & 99 & 149 & 1.01 & $0.76-1.35$ & 189 & 289 & 0.91 & $0.74-1.12$ \\
\hline & & $600-999$ & 266 & 394 & 0.96 & $0.80-1.14$ & 145 & 214 & 1.12 & $0.88-1.41$ & 260 & 391 & 0.97 & $0.81-1.17$ \\
\hline & & $\geq 1000$ & 3469 & 5009 & 1.00 & & 1684 & 2548 & 1.00 & & 3145 & 4519 & 1.00 & \\
\hline & & total & 4010 & 5817 & & & 1962 & 2939 & & & 3647 & 5264 & & \\
\hline & & trend & & & 0.94 & $0.76-1.17$ & & & 1.43 & $1.04-1.98$ & & & 1.09 & $0.86-1.39$ \\
\hline \multirow[t]{4}{*}{$5-9$} & \multirow{4}{*}{$\begin{array}{l}1962- \\
1989\end{array}$} & $0-199$ & 20 & 19 & 1.54 & $0.72-3.30$ & 22 & 22 & 0.71 & $0.36-1.43$ & 23 & 18 & 0.99 & $0.50-1.93$ \\
\hline & & $200-599$ & 94 & 90 & 0.97 & $0.69-1.36$ & 76 & 69 & 1.29 & $0.88-1.90$ & 90 & 89 & 1.04 & $0.74-1.47$ \\
\hline & & $600-999$ & 128 & 119 & 1.09 & $0.82-1.44$ & 112 & 101 & 1.12 & $0.83-1.50$ & 122 & 113 & 1.14 & $0.85-1.52$ \\
\hline & & $\geq 1000$ & 1861 & 1876 & 1 & & 1640 & 1664 & 1 & & 1992 & 2011 & 1 & \\
\hline
\end{tabular}




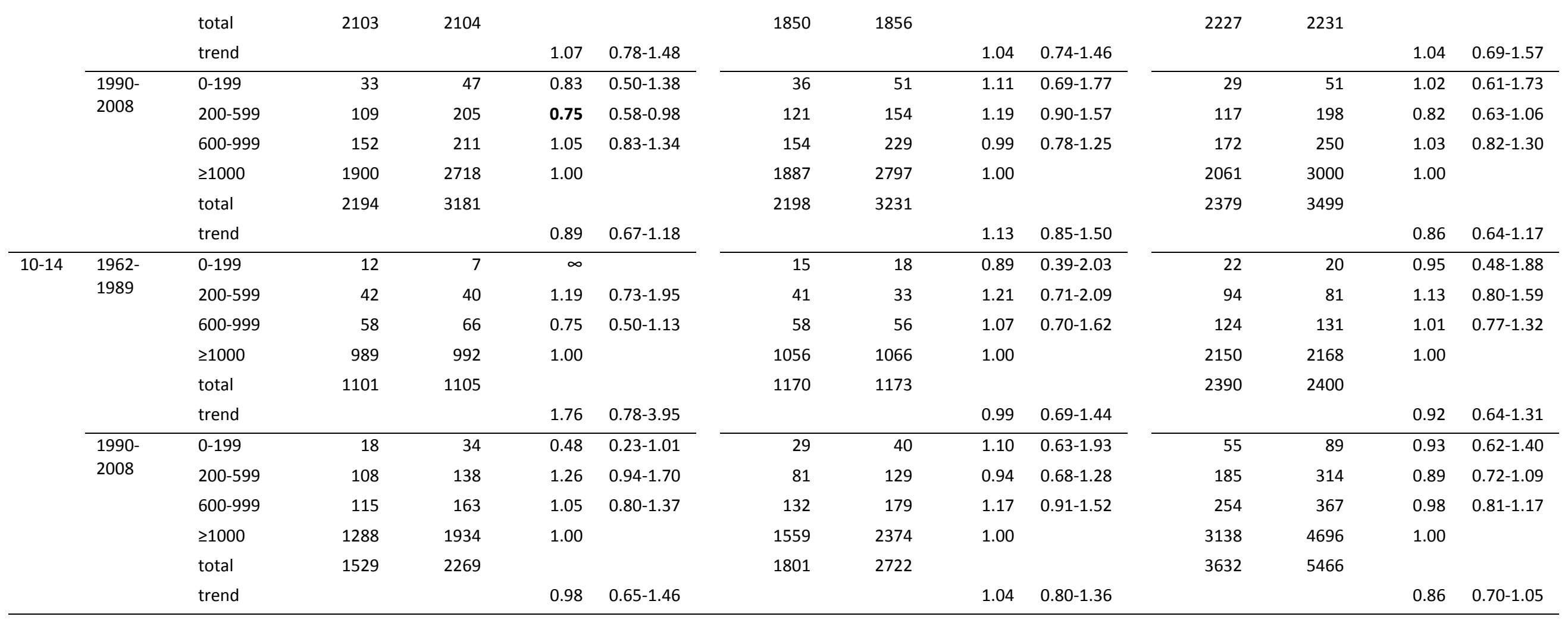

Table 1

Risks by age of case at diagnosis. In this and subsequent tables: bold indicates $p<0.05$, bold underlined indicates $p<0.01$. $\geq 1000$ is the reference category.

"Trend" is the increase in risk per unit increase of 100/d for the finer distance categories (see text). Risks are adjusted for socioeconomic status using Carstairs Index, an area-based measure. 


\begin{tabular}{|c|c|c|c|c|c|c|c|c|c|}
\hline \multirow{2}{*}{$\begin{array}{l}\text { Decade of } \\
\text { diagnosis }\end{array}$} & \multirow{2}{*}{$\begin{array}{l}\text { Distance to line } \\
\text { (m) }\end{array}$} & \multicolumn{4}{|c|}{ Lymphoid Leukaemia } & \multicolumn{4}{|c|}{ Acute Myeloid Leukaemia } \\
\hline & & Cases & Controls & $\mathrm{RR}$ & $95 \% \mathrm{Cl}$ & Cases & Controls & $\mathrm{RR}$ & $95 \% \mathrm{Cl}$ \\
\hline \multirow[t]{6}{*}{$1962-1969$} & $0-199$ & 9 & 3 & 2.01 & $0.37-10.99$ & 2 & 0 & $\infty$ & \\
\hline & $200-599$ & 23 & 17 & 1.54 & $0.77-3.09$ & 3 & 8 & 0.29 & $0.06-1.41$ \\
\hline & $600-999$ & 30 & 36 & 0.86 & $0.48-1.55$ & 11 & 7 & 1.94 & $0.58-6.56$ \\
\hline & $\geq 1000$ & 664 & 670 & & & 132 & 133 & 1.00 & \\
\hline & total & 726 & 726 & & & 148 & 148 & & \\
\hline & trend & & & 1.30 & $0.56-2.99$ & & & 2.67 & $0.19-37.97$ \\
\hline \multirow[t]{6}{*}{$1970-1979$} & $0-199$ & 29 & 18 & 1.98 & $0.96-4.09$ & 9 & 4 & 4.43 & $0.95-20.59$ \\
\hline & $200-599$ & 110 & 118 & 0.94 & $0.69-1.27$ & 26 & 25 & 0.88 & $0.46-1.69$ \\
\hline & $600-999$ & 168 & 155 & 1.08 & $0.84-1.39$ & 27 & 27 & 1.15 & $0.63-2.08$ \\
\hline & $\geq 1000$ & 2443 & 2459 & 1.00 & & 517 & 523 & 1.00 & \\
\hline & total & 2750 & 2750 & & & 579 & 579 & & \\
\hline & trend & & & 0.98 & $0.75-1.29$ & & & 2.91 & $0.73-11.61$ \\
\hline \multirow[t]{6}{*}{ 1980-1989 } & $0-199$ & 40 & 25 & 1.49 & $0.82-2.70$ & 10 & 5 & 4 & $0.85-18.86$ \\
\hline & $200-599$ & 142 & 128 & 1.10 & $0.83-1.46$ & 27 & 29 & 0.95 & $0.53-1.74$ \\
\hline & $600-999$ & 173 & 204 & 0.87 & $0.70-1.09$ & 33 & 36 & 0.83 & $0.49-1.41$ \\
\hline & $\geq 1000$ & 2469 & 2469 & 1.00 & & 474 & 476 & 1.00 & \\
\hline & total & 2824 & 2826 & & & 544 & 546 & & \\
\hline & trend & & & 1.05 & $0.76-1.46$ & & & 1.34 & $0.81-2.22$ \\
\hline \multirow[t]{6}{*}{ 1990-1999 } & $0-199$ & 53 & 54 & 0.87 & $0.56-1.37$ & 13 & 8 & 1.67 & $0.61-4.60$ \\
\hline & $200-599$ & 180 & 213 & 0.86 & $0.69-1.08$ & 29 & 38 & 0.85 & $0.48-1.50$ \\
\hline & $600-999$ & 220 & 212 & 1.01 & $0.82-1.25$ & 45 & 37 & 1.17 & $0.70-1.94$ \\
\hline & $\geq 1000$ & 2902 & 2896 & 1.00 & & 529 & 534 & 1.00 & \\
\hline & total & 3355 & 3375 & & & 616 & 617 & & \\
\hline & trend & & & 0.93 & $0.72-1.21$ & & & 0.96 & $0.48-1.92$ \\
\hline \multirow[t]{4}{*}{$2000-2008$} & $0-199$ & 40 & 92 & 0.75 & $0.50-1.13$ & 7 & 17 & 0.6 & $0.25-1.47$ \\
\hline & $200-599$ & 188 & 336 & 1.02 & $0.83-1.25$ & 34 & 66 & 0.92 & $0.57-1.47$ \\
\hline & $600-999$ & 221 & 430 & 0.96 & $0.80-1.15$ & 44 & 90 & 0.92 & $0.62-1.37$ \\
\hline & $\geq 1000$ & 2708 & 5228 & 1.00 & & 503 & 957 & 1.00 & \\
\hline
\end{tabular}


total

3157

6086

$0.75-1.19$

Table 2

Risks for subtypes of leukaemia. 


\begin{tabular}{|c|c|c|c|c|c|c|c|c|c|}
\hline \multirow[t]{2}{*}{ Region } & \multirow{2}{*}{$\begin{array}{l}\text { Distance to } \\
\text { line }(m)\end{array}$} & \multicolumn{4}{|c|}{ Cases diagnosed 1962-1989 } & \multicolumn{4}{|c|}{ Cases diagnosed 1990-2008 } \\
\hline & & Cases & Controls & $\mathrm{RR}$ & $95 \% \mathrm{Cl}$ & Cases & Controls & $\mathrm{RR}$ & $95 \% \mathrm{Cl}$ \\
\hline \multirow[t]{6}{*}{ All } & $0-199$ & 106 & 62 & 1.99 & $1.35-2.92$ & 115 & 177 & 0.82 & $0.63-1.07$ \\
\hline & $200-599$ & 355 & 334 & 1.05 & $0.89-1.25$ & 465 & 707 & 0.95 & $0.83-1.08$ \\
\hline & $600-999$ & 470 & 500 & 0.95 & $0.82-1.10$ & 577 & 822 & 1.01 & $0.90-1.14$ \\
\hline & $\geq 1000$ & 7264 & 7308 & 1.00 & & 7105 & 10331 & 1.00 & \\
\hline & total & 8195 & 8204 & & & 8262 & 12037 & & \\
\hline & trend & & & 1.09 & $0.92-1.29$ & & & 0.94 & $0.81-1.10$ \\
\hline \multirow[t]{6}{*}{ North } & $0-199$ & 7 & 3 & 0.71 & $0.12-4.28$ & 6 & 8 & 0.65 & $0.21-2.02$ \\
\hline & $200-599$ & 20 & 23 & 0.78 & $0.40-1.54$ & 19 & 35 & 0.80 & $0.43-1.49$ \\
\hline & $600-999$ & 21 & 35 & 0.66 & $0.36-1.20$ & 30 & 37 & 1.20 & $0.72-1.99$ \\
\hline & $\geq 1000$ & 396 & 383 & 1.00 & & 362 & 521 & 1.00 & \\
\hline & total & 444 & 444 & & & 417 & 601 & & \\
\hline & trend & & & 0.87 & $0.26-2.95$ & & & 0.93 & $0.51-1.70$ \\
\hline Yorkshire and & 0-199 & 7 & 4 & 1.68 & $0.49-5.77$ & 9 & 17 & 0.54 & $0.22-1.34$ \\
\hline \multirow[t]{5}{*}{ Humberside } & 200-599 & 21 & 17 & 1.18 & $0.58-2.41$ & 37 & 53 & 1.23 & $0.77-1.96$ \\
\hline & $600-999$ & 35 & 34 & 1.05 & $0.62-1.78$ & 47 & 74 & 0.94 & $0.62-1.42$ \\
\hline & $\geq 1000$ & 660 & 668 & 1.00 & & 612 & 896 & 1.00 & \\
\hline & total & 723 & 723 & & & 705 & 1040 & & \\
\hline & trend & & & 0.89 & $0.49-1.62$ & & & 0.75 & $0.41-1.38$ \\
\hline \multirow[t]{6}{*}{ East Midlands } & $0-199$ & 0 & 0 & - & & 1 & 1 & 1.23 & $0.07-21.41$ \\
\hline & $200-599$ & 5 & 2 & 2.44 & $0.47-12.62$ & 11 & 12 & 1.25 & $0.52-2.97$ \\
\hline & $600-999$ & 11 & 9 & 1.25 & $0.49-3.17$ & 16 & 17 & 1.33 & $0.66-2.67$ \\
\hline & $\geq 1000$ & 511 & 516 & 1.00 & & 500 & 751 & 1.00 & \\
\hline & total & 527 & 527 & & & 528 & 781 & & \\
\hline & trend & & & 5.67 & $0.06-496.14$ & & & 1.20 & $0.17-8.64$ \\
\hline \multirow[t]{4}{*}{ East Anglia } & $0-199$ & 0 & 0 & - & & 3 & 3 & 2.61 & $0.43-15.85$ \\
\hline & 200-599 & 12 & 11 & 1.38 & $0.55-3.43$ & 12 & 19 & 0.86 & $0.36-2.06$ \\
\hline & $600-999$ & 14 & 22 & 0.42 & $0.18-0.98$ & 27 & 29 & 1.33 & $0.75-2.38$ \\
\hline & $\geq 1000$ & 253 & 246 & 1.00 & & 203 & 294 & 1.00 & \\
\hline
\end{tabular}




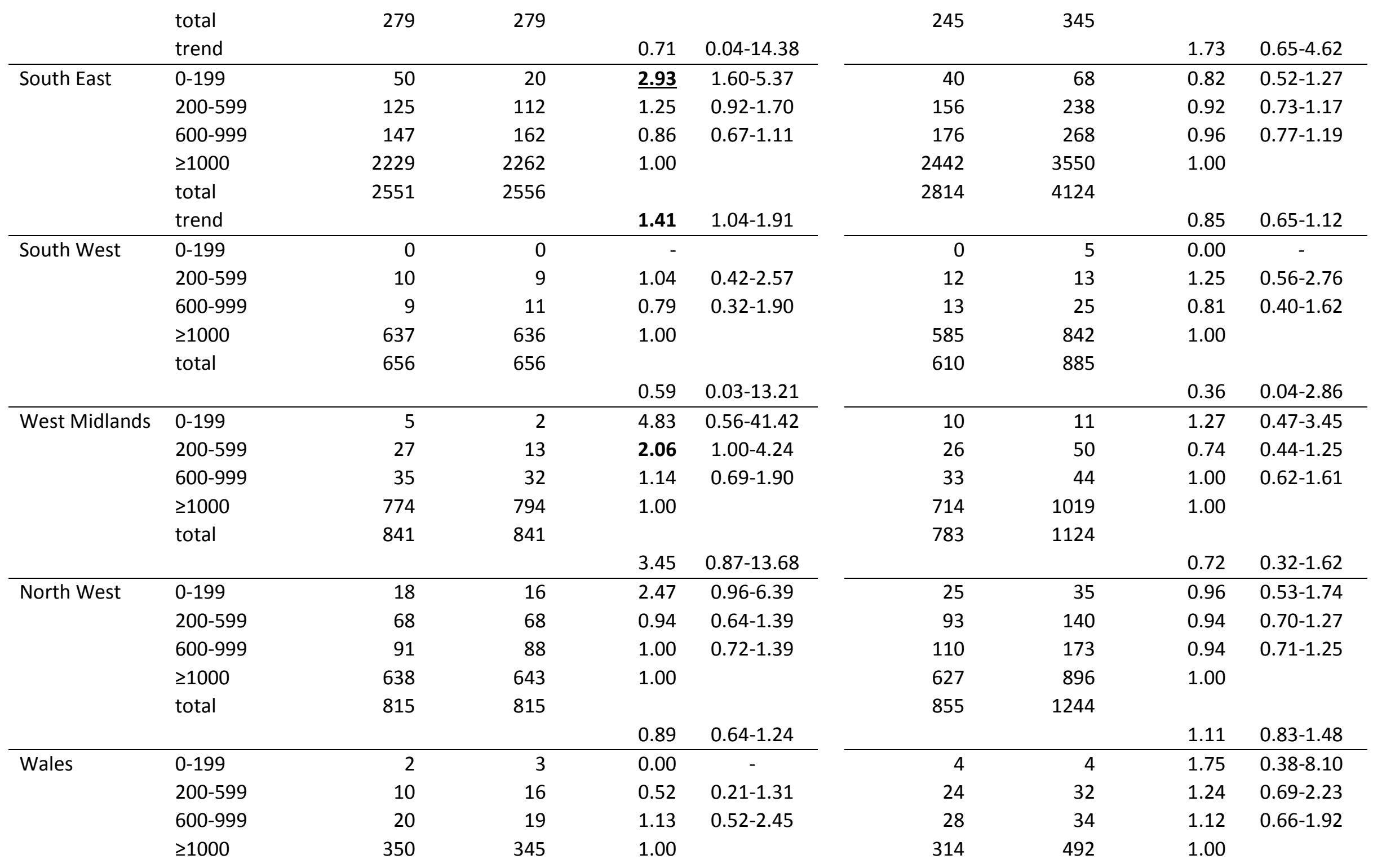




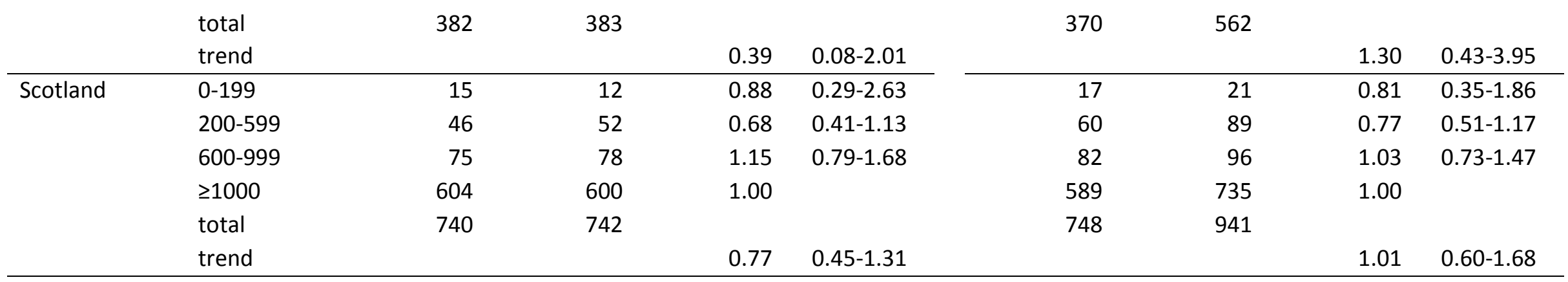

Table 3

Risks for leukaemia by standard region (ordered by conventional numbering of regions) 


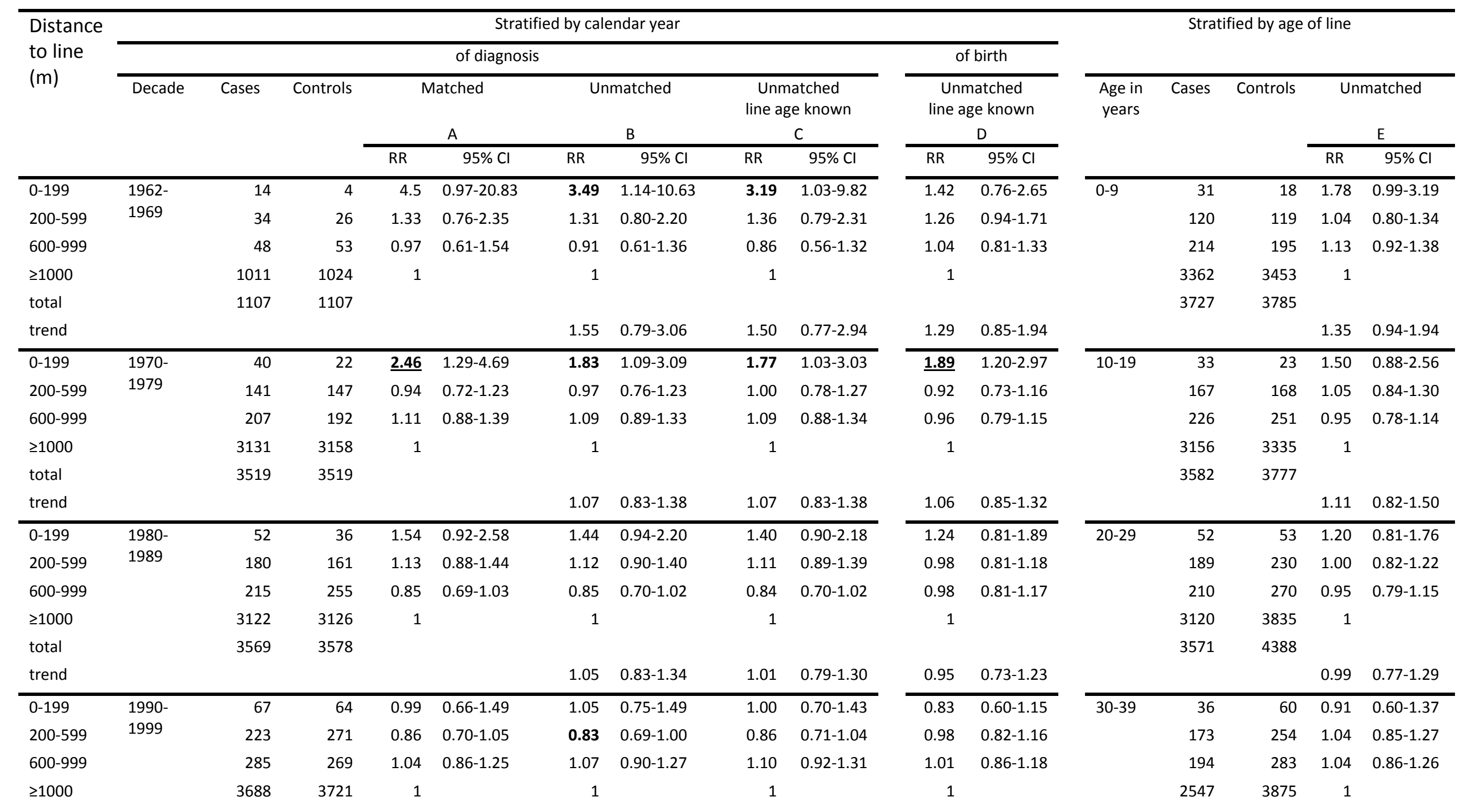




\begin{tabular}{|c|c|c|c|c|c|c|c|c|c|c|c|c|c|c|c|c|}
\hline \multirow{2}{*}{$\begin{array}{l}\text { total } \\
\text { trend }\end{array}$} & & \multirow[t]{2}{*}{4263} & \multirow{2}{*}{\multicolumn{3}{|c|}{4325}} & \multirow[b]{2}{*}{0.93} & \multirow[b]{2}{*}{$0.74-1.17$} & \multirow[b]{2}{*}{0.92} & \multirow[b]{2}{*}{$0.73-1.17$} & \multirow[b]{2}{*}{0.90} & \multirow[b]{2}{*}{$0.74-1.09$} & \multirow{2}{*}{\multicolumn{2}{|c|}{2950}} & \multirow[t]{2}{*}{4472} & \multirow[b]{2}{*}{0.91} & \multirow[b]{2}{*}{$0.71-1.15$} \\
\hline & & & & & & & & & & & & & & & & \\
\hline 0-199 & $2000-$ & 48 & 113 & 0.71 & $0.49-1.03$ & 0.81 & $0.57-1.13$ & 0.76 & $0.54-1.08$ & 0.82 & $0.47-1.40$ & $\geq 40$ & 53 & 79 & 0.96 & $0.67-1.37$ \\
\hline $200-599$ & 2008 & 242 & 436 & 1.03 & $0.86-1.23$ & 1.05 & $0.89-1.24$ & 1.06 & $0.89-1.24$ & 1.05 & $0.81-1.35$ & & 148 & 228 & 0.94 & $0.76-1.17$ \\
\hline $600-999$ & & 292 & 553 & 1.00 & $0.85-1.17$ & 1.01 & $0.87-1.17$ & 1.01 & $0.87-1.18$ & 0.96 & $0.76-1.22$ & & 163 & 266 & 0.88 & $0.72-1.08$ \\
\hline$\geq 1000$ & & 3417 & 6610 & 1 & & 1 & & 1 & & 1 & & & 1665 & 2504 & 1 & \\
\hline total & & 3999 & 7712 & & & & & & & & & & 2029 & 3077 & & \\
\hline trend & & & & & & 0.95 & $0.79-1.15$ & 0.95 & $0.80-1.15$ & 1.00 & $0.73-1.38$ & & & & 0.95 & $0.78-1.16$ \\
\hline
\end{tabular}

Table 4

Comparison of risks for leukaemia, by distance, stratified by calendar year and by age of line, both in decades. Unmatched analyses additionally adjusted for sex and birth registration subdistrict. Letters in column headings are referred to in text. 


\begin{tabular}{|c|c|c|c|c|c|}
\hline Variable & Odds ratio & $95 \% \mathrm{Cl}$ & standard error & $\mathrm{z}$ & $\mathrm{P}>|z|$ \\
\hline $\operatorname{sex}$ & 1.112 & $1.074-1.152$ & 0.020 & 5.90 & 0.000 \\
\hline Diagnosis decade & 0.862 & $0.845-0.881$ & 0.009 & -13.89 & 0.000 \\
\hline line age at birth of case & 0.999 & $0.978-1.020$ & 0.011 & -0.10 & 0.923 \\
\hline region & 1.021 & $1.013-1.029$ & 0.004 & 5.23 & 0.000 \\
\hline Carstairs quintile & 1.010 & 0.997-1.024 & 0.007 & 1.48 & 0.138 \\
\hline inverse distance (scaled) & 1.010 & $0.905-1.128$ & 0.057 & 0.18 & 0.858 \\
\hline
\end{tabular}

Table 5

Multivariate analysis of risks for distance 


\begin{tabular}{|c|c|c|c|c|c|c|c|c|c|c|c|c|}
\hline \multirow{2}{*}{$\begin{array}{l}\text { Field } \\
\text { strength } \\
\mu \mathrm{T}\end{array}$} & \multicolumn{4}{|c|}{ Leukaemia } & \multicolumn{4}{|c|}{ CNS/brain tumours } & \multicolumn{4}{|c|}{ Other diagnoses } \\
\hline & Cases & Controls & $\mathrm{RR}$ & $95 \% \mathrm{Cl}$ & Cases & Controls & $\mathrm{RR}$ & $95 \% \mathrm{Cl}$ & Cases & Controls & $\mathrm{RR}$ & $95 \% \mathrm{Cl}$ \\
\hline$\geq 0.4$ & 4 & 10 & 0.50 & $0.15-1.62$ & 4 & 8 & 0.61 & $0.18-2.06$ & 8 & 11 & 0.96 & $0.38-2.42$ \\
\hline $0.2-0.39$ & 3 & 8 & 0.49 & $0.13-1.88$ & 2 & 3 & 0.86 & $0.14-5.22$ & 6 & 5 & 1.65 & $0.49-5.49$ \\
\hline $0.1-0.19$ & 5 & 9 & 0.74 & $0.25-2.24$ & 4 & 5 & 1.14 & $0.30-4.35$ & 8 & 11 & 1.08 & $0.43-2.72$ \\
\hline$<0.1$ & 15908 & 19581 & 1.00 & & 11447 & 14531 & 1.00 & & 20994 & 26245 & 1.00 & \\
\hline total & 15920 & 19608 & & & 11457 & 14547 & & & 21016 & 26272 & & \\
\hline trend & & & 0.90 & $0.77-1.05$ & & & 0.98 & $0.92-1.04$ & & & 0.97 & $0.90-1.05$ \\
\hline
\end{tabular}

Table 6

Risks for calculated magnetic fields. $<0.1 \mu \mathrm{T}$ is reference category. Trend is RR per $0.1 \mu \mathrm{T}$ increase in field. 